\title{
Circular economy in the context of alterglobalization
}

\author{
Andriy Krysovatyy \\ Ternopil National Economic University, \\ Ukraine \\ rektor@tneu.edu.ua \\ Iryna Zvarych \\ Ternopil National Economic University, \\ Ukraine \\ irazvarych@gmail.com \\ Roman Zvarych \\ Ternopil National Economic University, \\ Ukraine \\ romazvarych@yahoo.com
}

Abstract. This article presents the circular economy as a new economic model, which focuses on the reuse of materials, as well as the creation of additional value through services and intelligent solutions. A number of indicators of the circular economy of EU countries, in particular, import and export of secondary raw materials from EU countries and non-EU countries, are analyzed; the indicator of circularity (9.1\%), indicating a significant circular gap - more than $90 \%$. A number of indicators within circular economic of EU countries are analyzed, particulary among imports and exports of secondary raw materials from both EU countries and non-EU countries, including the indicator of circularity $(9,1 \%)$, indicating a significant circular gap exceeding $90 \%$. Based on our research, we can outline leading European circular economics, including countries which have circular economics that can be considered to be either "outsiders" or "emerging". We propose to consider these distinations in the context of "economics of cowboys" vs. "an economy of space" as a manifestation of circular cognitive distance. To begin, we use the concept of a "circular city" from examples based upon Ljubljana, Copenhagen, San Francisco, London, and Zaanstad. The economic approaches of alterglobalization in the consideration of the circular economy are outlined. A regression analysis of the pre-conditions of alterglobalization is carried out. It is noted that the circular economy is considered as one of the imperatives of the alterglobalization. Various economic approaches depicting alterglobalization in the consideration of circular economics are outlined. A regression analysis of 
the pre-conditions of alterglobalization is carried out. It is noted that the circular economy is considered as an imperative within the context of alterglobalization. Main problems and perspectives of the circular economy in summery can be linked with the discussion of the existing economic paradigm. In our opinion, there is a need to move from a mechanical to an organic outlook, aimed at increasing environmental and social responsibility, that is, the formation of circular philosophy and consciousness.

Keywords: circular economy, alterglobalization, "economy of cowboys", "economy of a space", circular city, circular gap, circular countries, global "circular creditors", circular use leaders, circular outsiders, emerging circular countries.

JEL Classification: F18, F64, F68, Q5, Q56

\section{INTRODUCTION}

The circular economy is a new economic model in which emphasis is placed on the reuse of materials, as well as the creation of added value through services and intelligent solutions. A circular economy implies that the value chain is organized so that the outputs of one chain become inputs for another, reducing the dependence on new types of raw materials. The EU's main idea of a circular economy is the global eco-design, not simply set targets for recycling. The EU adopted a holistic, systematic approach to the circular economy. A starting point should be to optimize the circulation of costs, not the prevention of generated waste. In other words, the emphasis should be directed toward maximizing the reusage of waste as waste as raw materials or sources of energy. Throughout the world, over the next decade, the global economy needs a transformation to meet the needs of nearly 9 billion people. Over the next decade, the global economy will require transformation in order to accommodate the nearly a billion people. Each year, 8 million tons of plastic material is dumped into the oceans. The cumulative amount of waste flowing in the oceans, as well as the impact on the sea and, ultimately, the food supply, is still unknown. In the United Kindom, only $25 \%$ or 50 million toes tons of waste at landfills are disposed of annually, along with associated toxin-to-ground emissions and greenhouse gas emissions. According to current forecasts, the level of waste generated by the UK economy will double by $25 \%$ in the next 25 years, while including the availability of landfills and export routes to reduce sewage costs, the UK will have political pressure to find new solutions, which will yield more business opportunities. Pressures like these lead to the emergence of what is called the circular economy and is an alternative to the traditional linear economy (manufacturing, use, disposal), in which we store resources as much as possible, while extracting the maximum value during usage, which is followed by the restoration of products and materials, and then restore the products and materials.

\section{LITERATURE REVIEW}

\section{1. "Economy of cowboys" vs "economy of a space" - cognitive dissonance}

The concept of the circular economy can be considered as the ecological and economic state of the day, while at the same time, it reflects their interconnectedness with regard to usage of energy, materials and processes that are interrelated and conscious. In every circumstance, economic activity is interrelated with cyclical environmental (natural) and social (cultural) processes. Thus, in the traditional linear chain of 
cost creation, environmental problems in connection with the use of resources (inputs) often appear to be separated from economic problems due to pollution and waste management (extraction). An important aspect of the circular economy is that the efficient use of resources implies a holistic and contextual look at resource and waste management. This context applies to both natural and cultural resources. Porter and Van der Linde argued that, "it is important to use resources productively, regardless of whether these resources are natural, physical or human."

It is important to note that the "linear economy", which involves the growth of production and consumption by increasing the exploitation of natural resources, is referred to below as a "cowboy economy". This metaphor describes the American economy in the context when an individual travels west to take over new lands and resources from where they came were already.

Strategic decisions in the field of the circular economy are based on the operative definition of the complete process of procurement of raw materials, production, recycling and recycling as a whole (Ingebrigtsen \& Jakobsen, 2007). This means that the problems associated with the entry and exit are interrelated. The resource efficiency is based on a variety of types that have developed specialized qualities that maximize the use of limited amounts of available substance and energy. For example, water circulation systems allow this limited resource to be used in incredibly effective ways which sustains a wide variety of life. After all, everyone knows that there is a fixed amount of water on the planet, which constantly circulates in a cycle from the atmosphere to the ear this surface.

Ecosystems exist as examples of integrated collaboration between organisms with different properties and functions. An important characteristic of such ecosystems is that the basic elements of substances (inputs) and waste (extraction) depend on the future conditions and existence of these ecosystems.

This considered, CO2 is a vivid example of animal waste that is a necessary nutrient for plants. Thus, depending on the prospect, CO2 can be both a consumed element and a nutrient. A similar example is an excrement from animals, which is the basis of fertilizers for plants and microorganisms in the soil. Thus, microorganisms survive by plant and animal waste, while ensuring that the soil is rich in nutrients, which provides a basis of life for plants and animals.

Due to the complex interactions of different species, ecosystems ensure the maximum use of available resources. Thus, we can say that all species in an ecosystem are completely interdependent. In addition to the circulation of energy and matter in some ecosystems, there is also an exchange between different ecosystems that are interconnected though integrated networks.

An increase in the amounts of waste are examples of the uses of resources in the modern economy, which are very inefficient in comparison with the level of exploitation. According to the Norwegian White Paper "Waste Report" (NOU 2002), the amount of domestic waste has increased by more than $90 \%$ during the last 20 years. At the same time, GDP grew by only $60 \%$. Similar to the description of cycles in nature, one should speak of a sustainable economy which is based on the maximum use of available resources.

An important point in the circular economy is that promising activity must be increased to the mesolevel (Zvarych I., 2016). This means that decisions are not individualized, but are interactions between actors in defined (integrated) value chains - global circular value creation chains (including the global supply chain for secondary raw materials). Thus, solutions that lead to a positive effect on the cycle may be better, even if they do not create a sufficient degree of profitability for an individual actor.

In order to maximize the use of resources at the structural level, a change is required. It is especially important to create an arena in which the actors involved can coordinate their plans in order to achieve the best results possible. It is necessary to create a basis for making economic decisions, characterized by 
cooperative interaction. This new system exceeds the traditional difference between the market and the team economy because it reflects the rational interaction between independent actors at the meso level.

Since this does not mean that communicative actions should replace strategic actions in all areas, it is important to find out in which areas the participants should coordinate their activities, along with which areas they should compete in order to achieve the best economic potential and environmental performance. Thus, an important structural implementation of the cyclical chain of value is the creation of a communicative arena, where participants exchange information in necessary areas to achieve both effective and fair decisions.

When people in business and government become more supportive of overall stability, ideas and challengas can be achived and resolved by means of industrial revolution.

\section{THE CONCEPT OF "CIRCULAR CITY"}

In beginning, it will be essential for cities to play a main role during the transition to a circular economy. Urban areas are undergoing rapid growth on a global scale, and it is predicted that by $2030,60 \%$ of the world's population will be urbanized. Cities are strongly linked to economic growth, producing more than $75 \%$ of world GDP, which accounts for $75 \%$ of carbon emissions, consuming $75 \%$ of all world resources. It is clear that cities have leadership opportunities for pioneer lifestyles that will strengthen ecosystems and can contribute toward high social and economic well-being. In 2016, according to UN Sustainable Development Goals, 170 countries have agreed to a new urban development program that sets the global standard for sustainable city development and helps to revise modern planning and management.

This systemic approach of a circular economy can further contribute to the role of cities in solving key social, environmental and economic challenges in general. Currently implemented circular economy strategies with assistance from cities are already having a significant impact, which also feature a large amount of untapped potential. Sharing usage of cars, modular construction, sustainable management of organic waste, along with exploration of new consumption patterns can give cities the opportunity to take practical measures to reduce emissions, create new jobs, strengthen industry and competition, and increase overall health and well-being.

So what really sets a circular city aside in comparison with all other relevant city movements: smart cities, green, ecological cities, etc.?

A circular city is a movement which promotes and uses a systemic way of thinking that can provide economic, social and environmental benefits to cities, while maintaining economic rationale. Other frameworks are primarily focused around one aspectas either "green" or "eco" cities, which have strong environmental cases, but are without a practical economic Tens. Thus, the a circular city offers a more systematic approach that allows problem solving, while earning revenue and improving the quality of life.

Cities can be considered to be mirrows of our eonomy, which are responsible for more than half of the global population and $85 \%$ of the worls's GDP. So if we want to propel our economy forward, then cities need to be focus. In addition, cities can also be a catalyst for testing and can increase the impact of the circular economy. Due to the proximity of people, materials, and data in a small area, city open up opportunities for new business models such as reverse logistics, material gathering, reuse, rental and sharing. They offer a convergence point, with plenty of materials that, if utilized correctly, can create new opportunities. Additionally, creation of local markets will occur due to the abundance of people, along with the productions, and processes of local bissines models. Another thing that makes cities good candidates for the circular economy is that local politicians tend to be more flexible than national governments, heavier and more bureaucratic structures often exist. In addition, cities are certain to expand 
and grow over the next decades.

Almost half of the required infrastructure before 2050 has not yet been built, which provides us with a unique opportunity to avoid linear blicking that is currently exemplified especially here in the West.

Finally, there is digital technological development, which isn't particularly specifiz to cities, but quotes are much faster to adopt digital solutions, regardless if it be new applications, manufacturer ranges a exchange platforms, this technological development is blossoming in cities.

Generally, the population is open to new technology, and the concentration of people resources will only add momentum, and since it relates to genuine needs, such as rally distribution and gaps, its also important to consider the lack of space and expensive transportation.

There are a number of successful examples of such innovative circular activities aimed at achieving goals of sustainable development oriented towards implementing the ideas of the Fourth Industrial Revolution. Thus, special attention should be paid to the Slovenian capital of Ljubljana, which actively implements various models of circular economic relations. This is exemplified by Kabiné Šerinjon, which is a Slovenian clothing e-library. Kabiné Šerinjon is the name of a mobile platform that allows users to rent clothing and fashion accessories by Slovenian designers, along with a collection of clothing from the Reusable Center without any charge.

While being based on common consumption and joint use, this project contributes toward critical thinking and evidently challenges the ownership of new things through fostering cooperation between the faculties in Ljubljana (Faculty of Health Sciences, Faculty of Natural and technical sciences and the faculty of computer and information scince) in addition to the public waste management, "Snaga Ljubjana".

It encourages consumers to start thinking about justice, (joint) responsibility, sustainability, ethics and decision making (sharing, sharing, reuse of clothing).

Another circular project, which Slovenia is actively implementing, is the usage of the "Gorenka japansky" plant, spacifically its processing into paper.

Like other cities, Ljubljana also faces plants that are on the list of hundreds of the most invasive species in the world. In order to prevent excessive plant growth and to promote usage for cultural purposes, the city of Ljubljana teamed up with the Re-generationacija team, the Ljubljana University Botanical Garden, the Pulp and Paper Industry and the Snaga Public Transportation Storage Company. Ljubljana is one of the first cities in the world to produce paper from a Japanese mountaineer on a semiindustrial level. This serves as a perfect example of how a problem of invasive species was solved in an innovative way, which corresponds to the principle of circular economy.

On a final note, the paper products from this project were used to generate paper bags and notebooks.

A futher project related to this was the production of paper for recycling packaging for milk and juice. In 2015, the State holding "Javiny Holding Ljubljana" and public companies Snaga, "Ljubljana Template Projects", "Energy Ljubljana", "Ljubljana Parking in Trznice", "Jalle" and "Water Supply and Sewerage" began to use the most stable hygienic on the market in order to produse paper (paper towels and toilet paper), made from recycled packaging for milk and juice.

In this recycling process, separately collected packaging is delivered to the packaging company, where it is properly handled and returned to the manufacturer, in a closed circle.

A closed flow of materials such as this contributes to environmental and financial savings.

Along with the foregoing, other important technologies, such as the Internet of Things (IoT), artificial intelligence, are key factors in the development of the circular economy.

A scale of risks, threats and, accordingly, challenges of waste reduction and management suggests that there will be significant business opportunities. In order to take advantage of these opportunities, companies will need to review their business and financial models, while focusing on cost reductions and 
considering opportunities to capitalize on waste/product revenues.

Many businesses need funding to provide working capital and infrastructure support. For companies, it's important to get their advisors at an early stage so they can manage them with a range of affordable funding options.

At the heart of digitization is the "new infrastructure" needed to connect all things connected with the internet. This involves deploying a sensor network that collects data and provides a deeper understanding of the flow of materials, products, and information. This data can be analyzed to make more informed decisions about how we consume resources and how we design our systems.

In the Copenhagen Model, the city of Copenhagen combines environmental initiatives, economic growth and quality of life in realistic and innovative planning. Some features of the circular economy are jobs, economic growth, and better resource management.

An administration in Copenhagen called, "2025 Copenhagen Technical and Environmental Administration" has a vision for 2025 which introduces three goals with the titles, "living city", "city wth land", "responcible city".

A"Living City" involves improving everyday life in clean urban spaces, remaining the world's best city for cyclists, and more urban with green and blue areas. A "Responsible City" aims to become the first carbon-neutral capital, to not spend resources, to make the city more reliable and sustainable, ready to cope with future clamates.

Whithin the framework of the "Create Copenhagen"/"Responsible City", we want the majority of Copenhagen to use the schemes of sharing, transfer and reuse until 2025.

There is enough space to move all recycling centers into the city, as wellas some potential to work with some pilot programs elsewhere in the city.

As part of the recently adopted Action Plan on the United Nations Sustainable Development Goals, Copenhagen will develop guidelines to enable citizens, institutions, and enterprises to work towards accomplishing goals in their daily work. The manual will include introductions to these goals, a list of proposed activities and communication to educate citizens and engage them in more sustainable behavior.

The city also works with the involvement of citizens to separate their waste and to eliminate litter, which is exemplified by the fact that public waste containers are visible and paint green steps on the sidewalk in the garbage dumps.

Presently, the city is implementing city-wide schemes for the separate collection of biological waste: The Council initially decided to implement schemes in September 2016, which was successfully achived in the fall of 2017.

Copenhagen is focused on deciphering of plastic waste from burning waste/waste to energy to become neutron gas by 2025. Since 2011, we have been conducting a series of pilot programs to get information about effective ways to process plastic and debunk myths about how difficult it is to recycle plastics. This involves working with businesses, research institutions and associations to find innovative solutions.

Copenhagen wants to cooperate with stakeholders in the value chain because it is well known that stakeholder knowledge is often confined to certain parts of the value chain and this may hinder the search for a solution that meets the requirements of the circular economy. Without the knowledge of the waste management process, the designer will not be able to build waste or design the product for reuse, disassembly, or recycling. In addition, if the waste management industry does not know the requirements of production processes, it will not be able to produce raw materials that can replace unused materials. So somehow these two ends.

To achieve a "real" circular economy, it is important to scale up. This means attracting large (multinational) companies to the circular economy so that they have the incentive to create products and 
services in accordance with circular principles. Although cities have a significant impact through public procurement, it is not always enough to change the business models of large companies to make products more durable, recoverable, reusabl, etc.

This process is demonstrated by the Finnish company Enevo, where sensors have been installed in order to collect and analyze date from gabage cans.

These sensors provide information about when trash cans are filled up, allowing Enevo systems to optimize tolls for trucks. As a result, Enevo customers report savings of between $20 \%$ and $40 \%$, due to reduced fuel consumption and costs associated with handling loads and labor, and to a reduced number of collections.

A similar situation can be observed both in San Francisco and London, where automatic solar storage tanks warn local authorities when they are full, along with creation of perfect garbage collection routes and reduced operating costs by $70 \%$.

When such infrastructure is built and large amounts of data are collected, technological advances that use large volumes of data and artificial intelligence algorithms will allow for deeper and more detailed analysis. These technologies combine and process an enormous amount of information to create models and cover issues that would not have been commonly found, or at least not without significant investments in time and resources.

Another example is highlighted in the Dutch city of Zaanstad. This city is built on drained lands, and therefore repairing the foundations of buildings is a serious and expensive problem. To address this problem, the Parteon Housing and Communal Services Office have been working with scientistsfrom Berenshot Intellers in order to develop a prediction algorithm, based on the needs immediate repairs. The project was linked to more than 135 million housing records from the municipality and Parteon, data from the Kaasters infrastructure, weather data from the Royal Netherlands Meteorological Institute and SkyGeo satellite data. Thus, Parteon was able to detect more than 11,000 homes to be considered at risks, saving significant time and resources for the repair of these houses.

Artificial intelligence at a more advanced stage has led to such achievements as unmanned cars that can significantly change not only how we move but also how we build and develop where we live. Thus, cars are no longer property but are divided between different owners. Autonomous transport programs are being piloted all over the world in partnership with various technology companies. One such example is the "nuTonomy", which has been manned by an autonomous vehicle which were in Singapore since 2016. Their initial pilot program had six autonomous vehicles modified by Renault Zoes and Mitsubishi iMiEVs. Since then, nuTonomy has partnered with the local Raidserring company Grab, with plans to work together in 2018.

One more progressive and innovative example of the successful implementation of the circular economy is the "High 5", a company in Belgium that has created a way to sort different colored glass using automation technology. This is the first plant in the world that sorts input streams to separate the four colors needed to make bottles and other hollow glass containers such as pots and jars. Their purpose is to increase the proportion of recycled glass in the manufacture of double-glazed windows.

Lastly, one more company that embodies innovation and successful implementation pf the circular economy is Fater Spa, which is company with the slogan, $0 \%$ waste - 100\% new life - this is the priority of Fater SpA. Fater Spa demonstrates the world's first industrial complex capable of processing almost 100\% of used hygiene products for absorption (diapers for babies, women's sanitary napkins) and turning them into secondary raw materials such as plastic, and cellulose. Fater Spa plant is unique, which is the first of its kind in the world, and demonstrates industrial technological efficiency, processes 10 thousand tons of absorbent hygiene products per year and serves about a million consumers. Fater SpA's technological patents are in a joint venture with P \& G and Gruppo Angelini. This company is an example of the 
industry's contribution to environmental sustainability, and was deservedly nominated from the European Commission Circular Economy Champion.

\section{INDICATORS OF THE CIRCULAR ECONOMY OF EUROPEAN COUNTRIES}

As already noted, a truly circular economy is more than just a closed economy. Given the global metabolism of material as the starting point (the material used), it is worth evaluating circularity. As of 2015, the extracted resources amounted to 84.4 billion tons (four groups of resources: minerals, fossil fuels, metal ores and biomass). In order to control all annual material costs, extractive resources are complemented by resources from the worked cycle. In 2015, the world economy used 8.4 billion tons of circular resources (spent), which allowed the usage of 92,8billion tons of material resources. Of these materials, which annually enter the world economy, most (56.8 billion tons) are used by society as products that have a short operating period (fast spoil), reaching end-user, as a rule, during the same year. The remainder of the 36 billion tons mentioned earlier is transferred into a long-term stock. After meeting the needs of society, the release of resources is generated in the form of household waste, emissions, and destruction. Most of the waste comes from long-term stocks, for example, waste of infrastructure and housing or scrap.

In order to assess the circularity of the economy, the circularity indicator is used. Consequently, the global circularity metric was estimated at $9.1 \%$ by 2015 : Circular materials (secondary raw materials) / Extracted resources $=8.4$ billion tons $/ 92.8$ billion tons $=9.1 \%$

The value of $9.1 \%$ for the indicator of the circularity of the economy indicates a significant gap, a circular gap that exceeds $90 \%$. Despite the fact that our current economy is predominantly linear, it is advisable to provide a context in which it can be used in practice.

Consequently, the global circularity metric (GCM) is a highly simplified dimension for a very complex system. Calculation and interpretation of the GCM has one important strength and at least four practical tasks, in other words, the threats or challenges that are inherent in the modern global economy:

- Production and consumption

- Waste management

- Secondary raw materials

- Competitiveness and innovation

- Private investments, jobs, and gross value added related to circular economy sectors

- Patents related to recycling and secondary raw materials

Generation of municipal waste per capita:

At the end of 2016, the volume of household waste production varied considerably: from $777 \mathrm{~kg}$ per capita in Denmark to $261 \mathrm{~kg}$ per capita in Romania. Variations reflect differences in patterns of consumption and economic wealth, but also depend on how household waste is collected and managed. There are differences between countries as to how waste from trade and administration is collected and managed along with household waste. Consequently, in 19 of the 31 countries (the Member States and EFTA), per capita household waste production increased between 2000 and 2016.

The highest average growth rates were recorded for Malta (2.5\%), Greece (2.4\%), Latvia (2.1\%) and Denmark (1.9\%).

Max dates Denmark 762, Germany 626, Cyprus 640, Norway 754, Switzerland 720.

The largest reduction occurred in Bulgaria, with an average annual decrease of $-2.5 \%$, followed by Romania $-1.3 \%$ and Slovenia $-1.2 \%$.

The recycling rate of municipal waste:

Thus, the highest level of household waste recycling was recorded in Germany, followed by Belgium, 
Denmark, France, Italy, Slovenia, Sweden, and Montenegro (see table 1). In 2016, the largest gap of increasing levels of recirculation was typical for Lithuania, Bulgaria, Czech Republic, Luxembourg, and Poland. It's important to note that Germany has the best recycling standards in the world. Austria ranks second, followed by South Korea and Wales. All four countries managed to recycle from 52 to $56 \%$ of their total municipal waste. Switzerland, in fifth place, processes almost half of their municipal waste.

Table 1

European circular countries

\begin{tabular}{|c|c|c|}
\hline Circular use leaders & Circular outsiders & $\begin{array}{c}\text { Emerging circular } \\
\text { countries, 2016 }\end{array}$ \\
\hline Netherlands & Greece & Ireland \\
\hline Italy & Romania & Czech Republic \\
\hline France & Ireland & Croatia \\
\hline Belgium & & Latvia \\
\hline United Kingdom & & Malta \\
\hline Poland & & Poland \\
\hline Luxembourg & & Portugal \\
\hline Estonia & & Romania \\
\hline Germany & & Slovenia \\
\hline Malta & & \\
\hline
\end{tabular}

Source: Own study based on http://ec.europa.eu/eurostat/data/database.

The recycling rate of all waste excluding major mineral waste:

Thus, in general, the EU (28) is characterized by an average recycling rate of (50-60\%). The highest values are reported for Luxembourg (90\%), Belgium (80\%), Slovenia $(60-70 \%)$, the Netherlands $(70 \%)$, and Italy (60-70\%) (see table 2).

Some of the lowest rates are characterized by Greece (10-20\%), Bulgaria (15-20\%), and Estonia (20$22 \%)$. It is also important to note the countries with the highest positive dynamics: Croatia $(25 \rightarrow 40 \%)$, Latvia $(40 \rightarrow 61 \%)$, Slovenia $(50 \rightarrow 75 \%$ ) (see chart $1,2,3$ ).

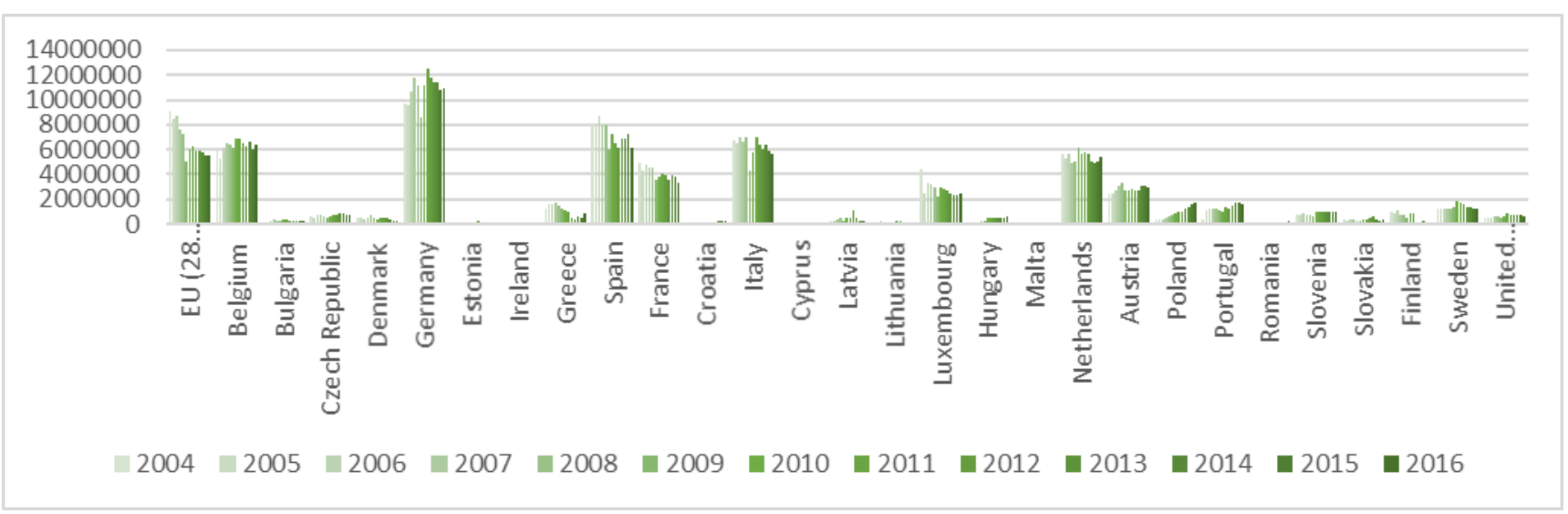

Chart. 1. Trade in recyclable raw materials (imports) - tonne

Source: Own study based on http://ec.europa.eu/eurostat/data/database. 


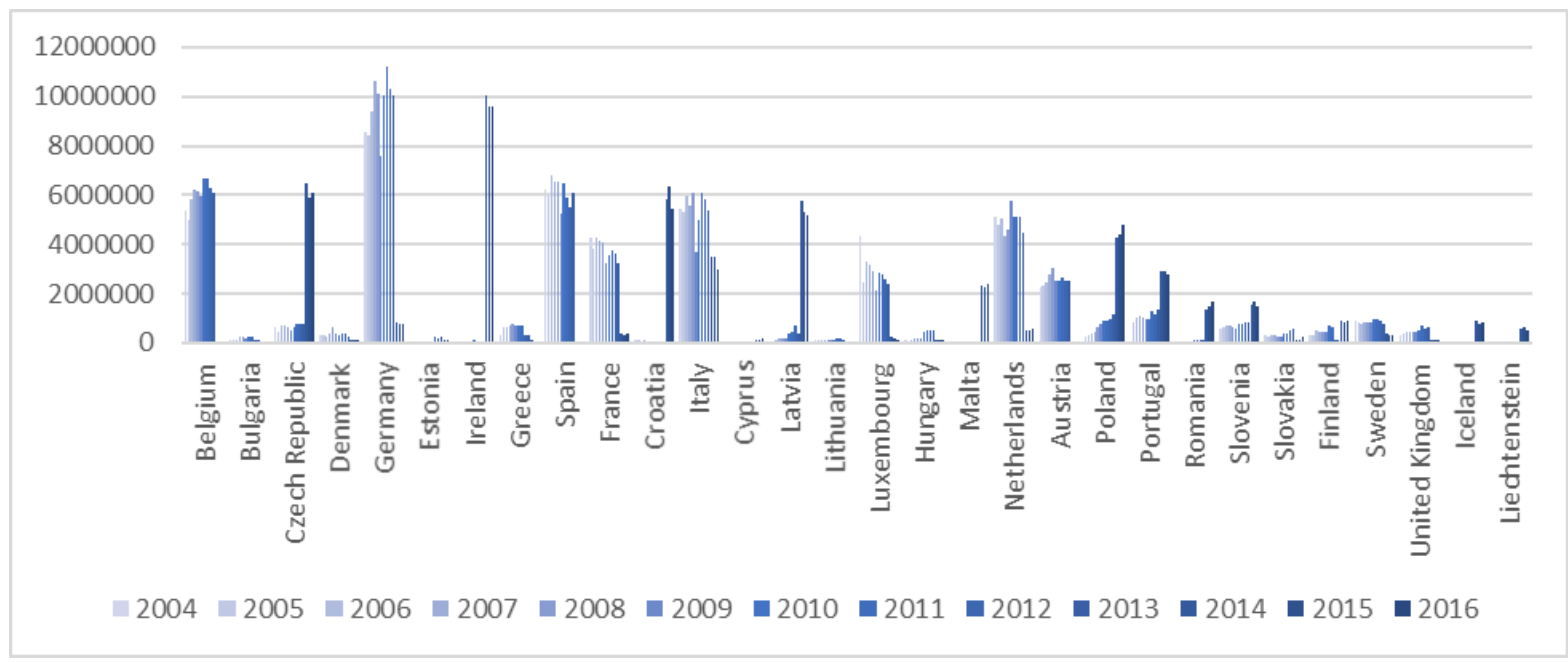

Chart 2. Recyclable raw materials imported by EU countries

(Internal imports of recyclable raw materials from EU countries) Source: Own study based on http://ec.europa.eu/eurostat/data/database.

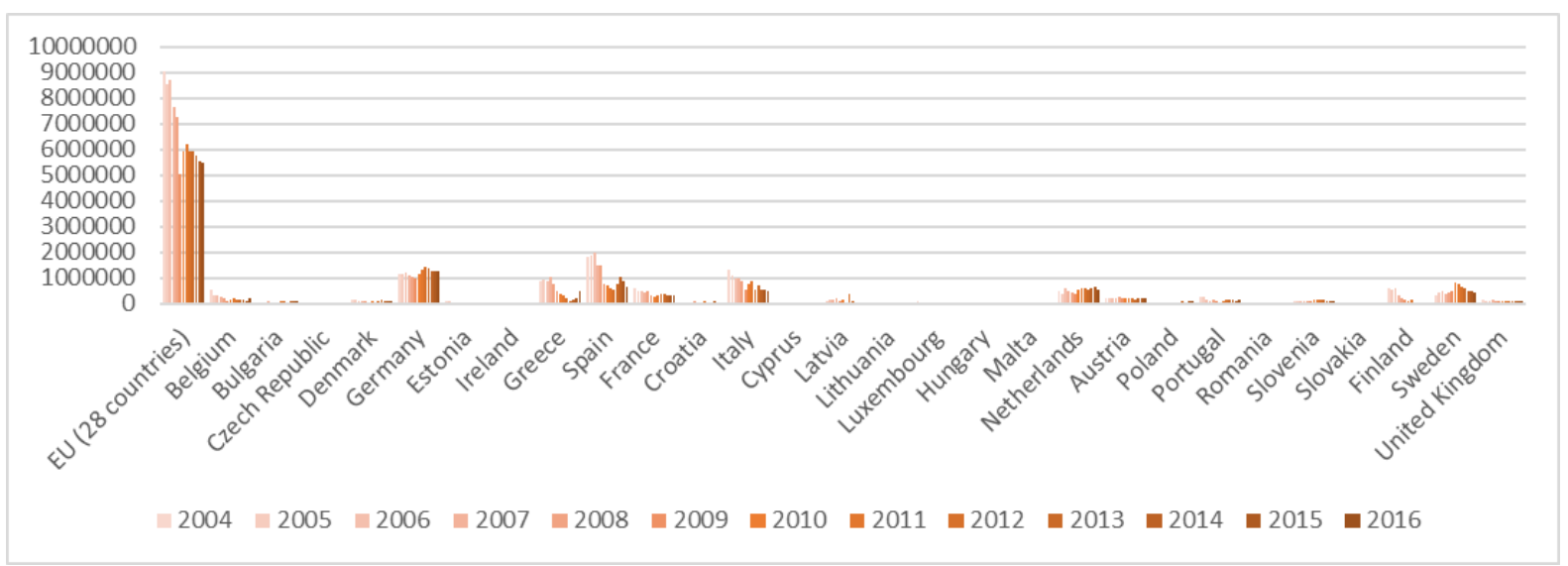

Chart 3. Recyclable raw materials imported by non-EU countries (recyclable raw materials) Source: Own study based on http://ec.europa.eu/eurostat/data/database

Returning secondary raw materials defined as waste to the cycle of resources is an important element of sustainable resource management. Germany plays a pioneering role here at both the European and global levels. A breakthrough came in 1996 with the Closed Substance Cycle and Waste Management Act, which linked product responsibility and resource protection together with product-related regulations on packaging, batteries, exhausted vehicles and discarded electrical/electronic goods. This act created the regulatory framework for resource-efficient economic activity. The pretreatment requirement in effect since June 2005 for biodegradable (municipal) waste containing organic material prior, to landfilling has made a major contributions towards closing substance cycles by bringing about an increased separation and thus a better use of recyclable materials from waste. 
Top global "circular creditors"

\begin{tabular}{|c|c|c|c|c|}
\hline $\begin{array}{c}\text { Top exporters of } \\
\text { recyclable raw materials }\end{array}$ & $\begin{array}{c}\text { Top exporters to non-EU } \\
\text { countries }\end{array}$ & $\begin{array}{c}\text { Top importers of } \\
\text { recyclable raw } \\
\text { materials in EU }\end{array}$ & $\begin{array}{c}\text { Min imports of } \\
\text { recyclable raw } \\
\text { materials }\end{array}$ & $\begin{array}{c}\text { Top importers from } \\
\text { EU countries }\end{array}$ \\
\hline Germany & United Kingdom & Germany & Estonia & Germany \\
\hline France & Netherlands & Spain & Ireland & Belgium \\
\hline Netherlands & Germany & Italy & Croatia & Spain \\
\hline United Kingdom & Belgium & Belgium & Malta & \\
\hline & & Netherlands & Lithuania & \\
\hline & & France & & \\
\hline
\end{tabular}

Source: Own study based on http://ec.europa.eu/eurostat/data/database.

For some materials - copper, for instance - Germany currently has the highest recycling rate in the world (D 54\%; EU 45\%, USA 41\%, world 13\%) (see chart 4, 5).

Recycling rates for other major raw materials within Germany are listed at: 35\% for aluminium, 59\% for lead, $90 \%$ for steel, $20-25 \%$ for cobalt and 10\% for molybdenum.

Germany's use of secondary raw materials also reaches impressive levels: from 45\% for steel, and up to as much as $94 \%$ for glass. These recovery rates for main currents of waste are all well over $60 \%$, whereas for construction and demolition waste reaches $88 \%$. Approximately $92.3 \%$ of exhausted vehicles are recycled, and the recycling rates for packaging waste range from $68 \%$ up to $93 \%$, depending on the material.

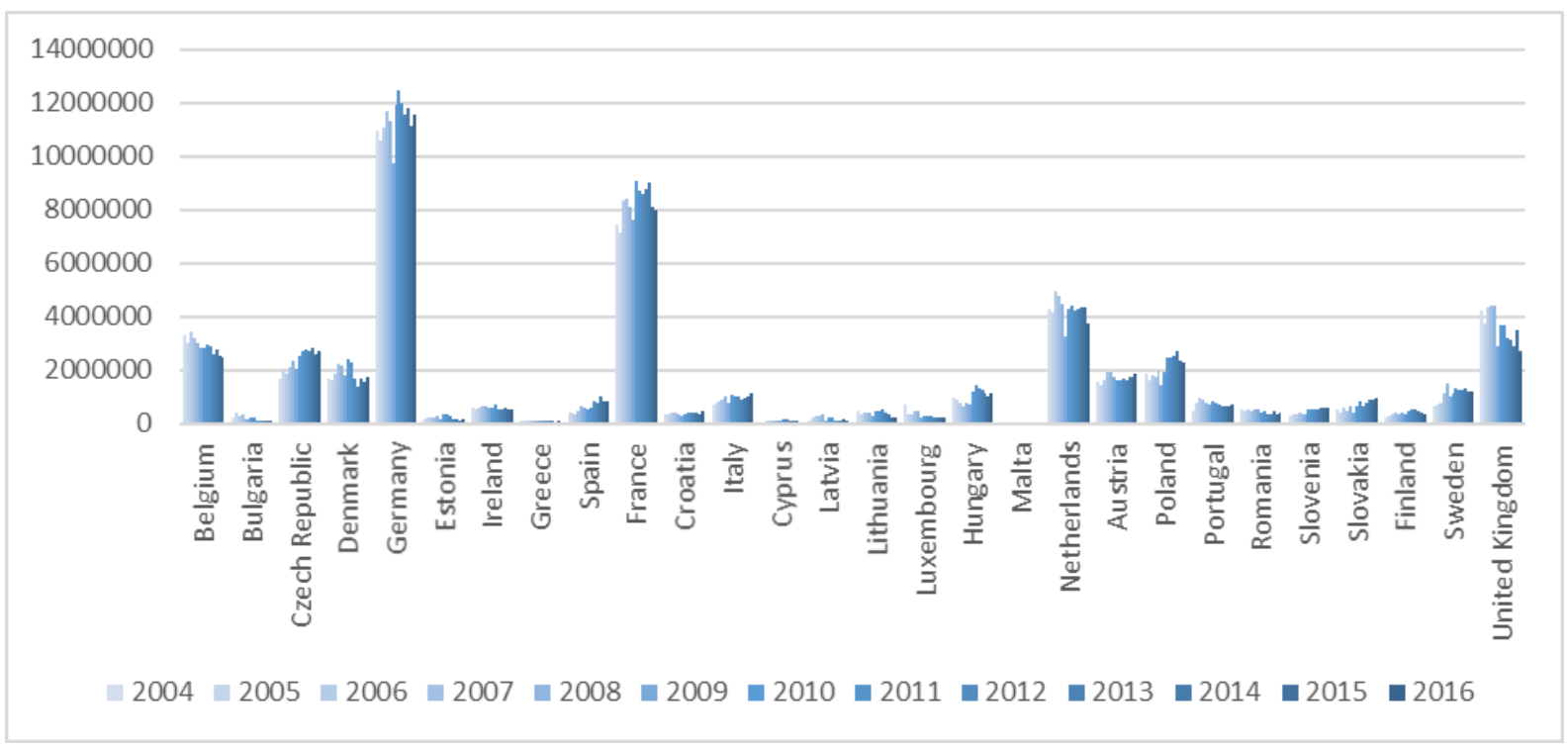

\section{Chart 4. Recyclable raw materials exported to EU countries of recyclable raw materials}

Source: Own study based on http:/ / ec.europa.eu/eurostat/data/database.

In 2009, Germany's total recycling rate hovered at 70 percent. In 2015, the most recent available data, the recycling rate was a strong 79 percent. Germany actually leads the EU when it comes to recycling municipal waste, according to Eurostat data. Here are the top five EU countries of municipal recycling rates for 2015:

- Germany: $66.1 \%$ 
- Austria: $56 \%$

- Slovenia: $54.1 \%$

- Belgium: $53.4 \%$

- Switzerland: $52.7 \%$

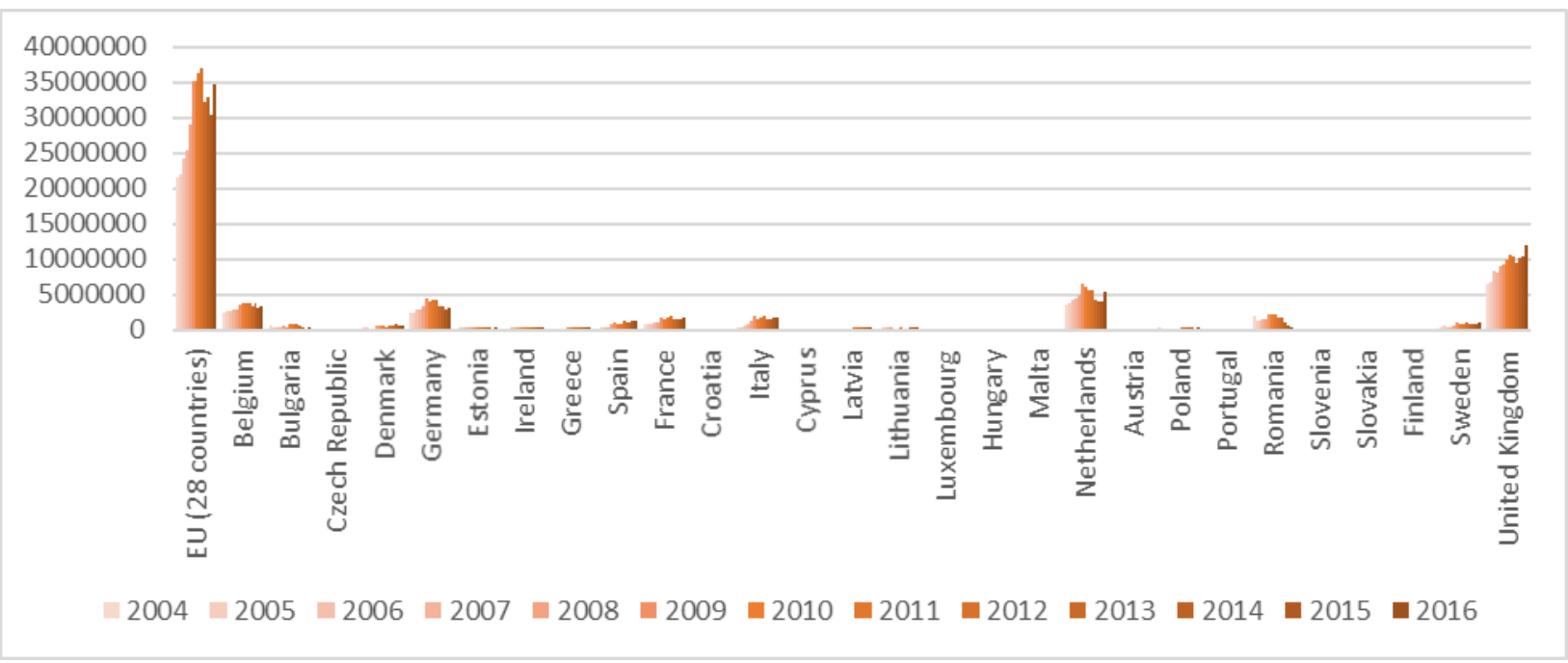

Chart 5. Exports to non-EU countries of recyclable raw materials

Source: Own study based on http://ec.europa.eu/eurostat/data/database.

In this way, the global circular economy requires the implementation of the four main stages aimed at overcoming the breakdown (degree) of circularity:

- creation of a global circular coalition with a common philosophy;

- development of global integrity and an order of action;

- global goals - local actions;

- circular systems.

Given the current global economic trends and available technologys, the entire circular economy can only be realized in the long run.

There are four main reasons for this:

1. Society is still building up a stock of rare materials, mostly rare earth metals, needed for the latest innovative and complex products;

2. Economies of emerging and developing countries are still accumulating a stock of active resources and environmental infrastructure;

3. Technical capabilities are not sufficient to completely close the cycle, and many processes still demonstrate a loss of both quality and quantity of material;

4. Some materials, including certain minerals, such as the Feldspar group, may be available in large amounts, especially in certain geographical regions.

\section{ECONOMIC APPROACHES OF ALTERGLOBALISATION}

Modern world economic development is asynchronous, unstable, and as a result, it forms a unipolar world. The establishment of global economic contacts is an indirect process of relations between national economies. However, the existence of global contacts shows the collision between national priorities and the global scales of economic and public life in general. There is a certain methodological contradiction in 
understanding the essence, structure, and logic of modern globalization processes - from the negation of globalization to its absolutization. This contradiction and the large interdisciplinary range of research make the assumption that the phenomenon of globalization is ambiguous and controversial. The process of alter-globalization is gradually replacing the process of globalization and these changes are irreversible the modern business philosophy should be transformed. Alterglobalization is the process of alternative global economic, political and cultural integration, aimed at the diffusion of global transnational influence, ecological-local stability, and human-centeredness. If globalization demands benefits from unification, the process of alter-globalization involves the benefits from uniqueness, diversity, and comprehensiveness of its participants.

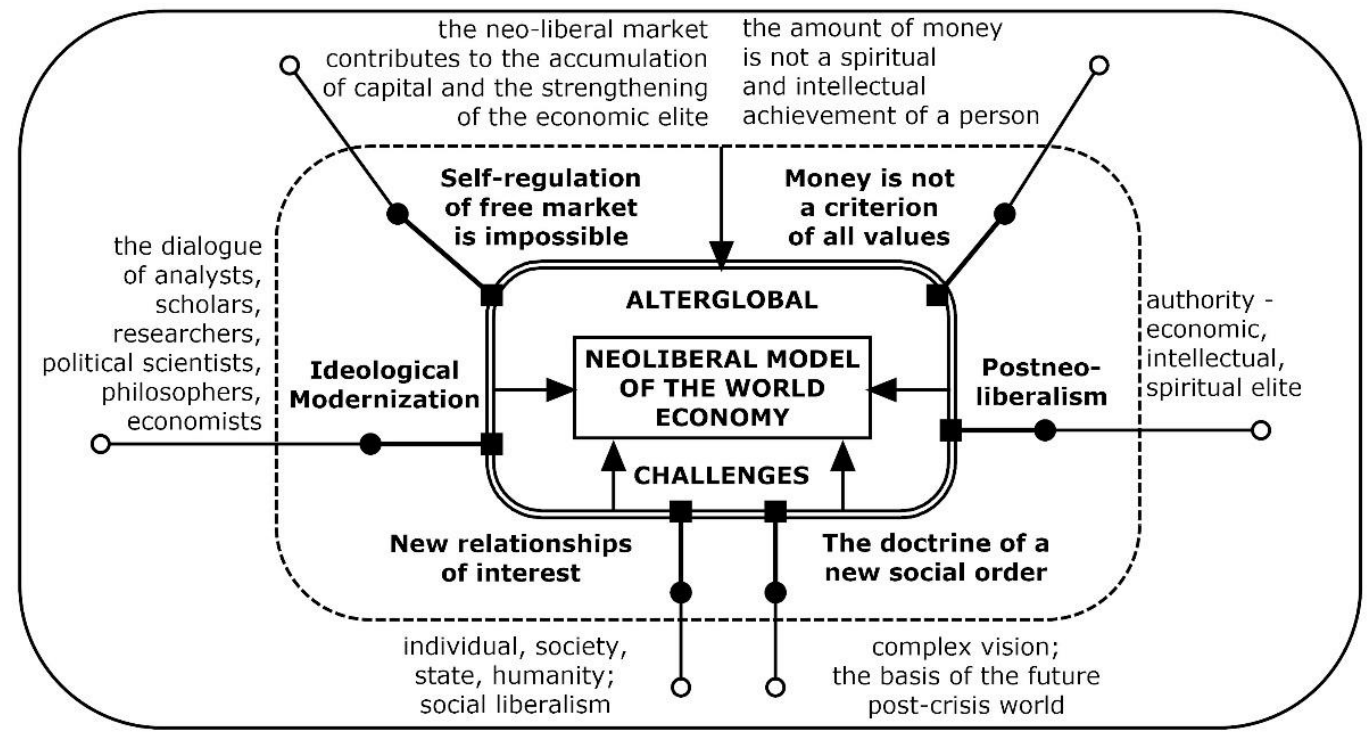

Chart. 6. Alter-global challenges of the neoliberal model of the world economy Source: Own study.

The unequal distribution of the benefits that globalization poses threaten conflicts at the regional, national and international levels. The rapid growth of poor countries is typical only for a small group of countries in SouthEast Asia, where the leeser-developed countries have lower growth rates than rich countries. As a result, there is income polarization but not convergence or equalization. In this process, countries with rapid economic growth can convergence to the richest countries, and poor countries will increase their lag in time. The growth of the income gap creates dissatisfaction from the poor countries, which can lead to international conflicts, as poor countries seek to join the "club" of rich countries and are ready to fight them for their share in world production. The critical imperatives of globalization are social inequalities, degradation of the environment, production fragmentation, reduced competitiveness of industrial and agricultural enterprises in developed countries, and the growing threat of impact on culture.

The growth of global social inequality destroys the base of political stability at both the national and global levels. Thus, any sustainable society should be sure that:

(a) the rate of resource use does not exceed the rate of regeneration;

(b) the rate of consumption of resources does not exceed the standards for the commissioning of renewable substitutes;

(c) the emission of pollutants and the accumulation of waste does not exceed the rate of their harmless absorption. 
However, economic globalization is harmful to the environment, because it depends on its own viability: the constant increase in commodity consumption, increased use of resources and the growing disposition of polluting waste in the ocean, both on the ground and in the air. The main feature of globalization is export-oriented production, which is destructive as it enhances global transport activity and uses fossil fuels, refrigeration equipment, and new ecologically destructive elements of infrastructure (construction of dams, ports, roads, airports, canals, and pipelines). In the agricultural sector, the transition to industrial and export systems damages soils and water, through poisoning them with pesticides, while contaminatiny genetically modified plants. Globalization accelerates the modification and privatization of resources of fundamental importance to life (fresh water); appropriates world-wide assets (air, oceans), turning them into landfill for waste; depresses the ability of countries to ensure their own environment and to develop health rules; destroys the historical ties of farmers with the land through industrialization and ecological distancing; substitutes homogeneity, monoculture and biodiversity; and directly serves unmanaged corporate power.

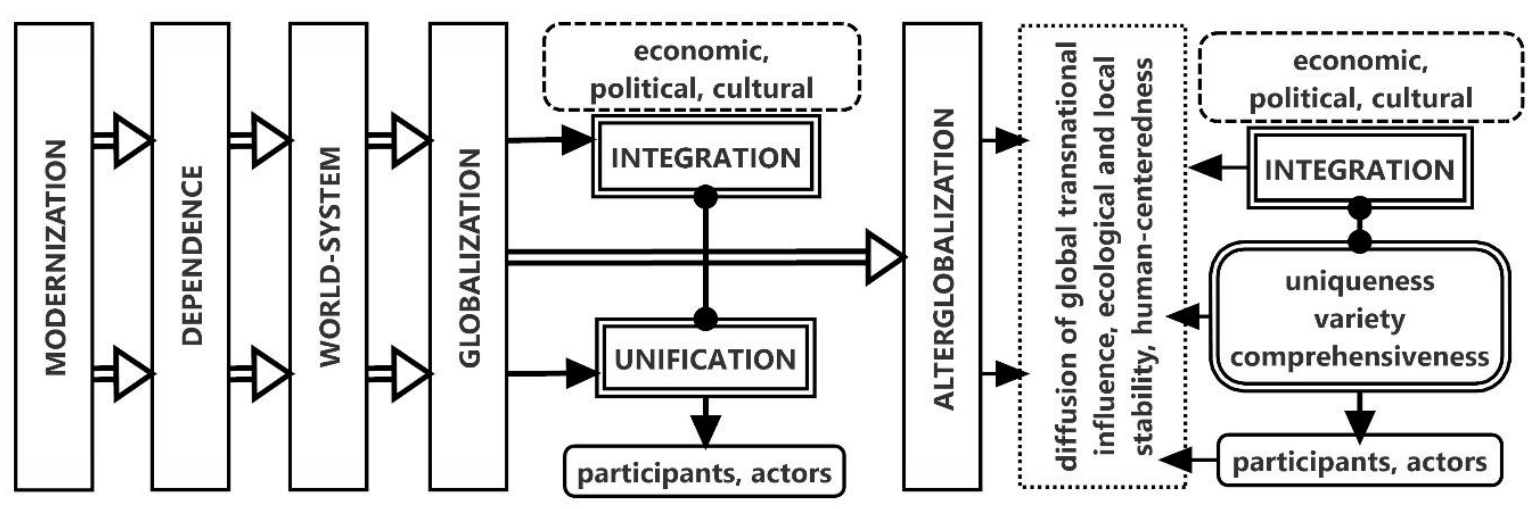

Chart. 7. Interpretation and formation of the alterglobalization theory

Source: Own study.

Alterglobalization is oriented towards self-determination for peoples, communities and nations by (a) local and national ownership and control over resources and productive assets; (b) local and national normative authorities in a system where central levels of government maintain a local level in terms of achieving self-determination goals; (c) maximizing local and national self-sufficiency in ways of meeting needs using local and national resources. The domination of local ownership and political power decreases the external dependence on reducing the competitive struggle for jobs, markets and material resources. However, this does not equate to isolation. Sustainable societies are good neighbors, that take participation in cooperative, peaceful and mutually beneficial relations with all parties through trade, cultural exchange, and exchange of information and technology. The problem will not be solved without profound fundamental changes in all aspects of its formation. Considering the presence of global problems such as climate change, it is important to transform the system with the mandatory observance of the basic rules of environmental sustainability. Today offers an opportunity to implement a new system that completely transforms the current dominant hierarchy of values, in which stability was left out of focus, and corporate income served as the top priority.

Consequently, economic globalization causes delocalization and increased disability of local communities and economies. However, a high percentage of people on earth survive at the expense of local, collective activities: small-scale farming, local markets and production for local consumption. This traditional system provided people with the opportunity to control they're own economic and food 
security, as well as to maintain the viability of communities and cultures. Even in developed countries, livelihoods have traditionally been associated with local economic production. Economic globalization has destroyed this system in favor of export-oriented economies, headed by global corporations. This led to the elimination of local (means of existence), jobs, and significantly reduced the self-sufficiency of local communities (see chart 6,7 ).

\section{CONCLUSIONS}

The economy of circulation will have a radical impact both on economic theory and on the implementation of economic practices. It is not enough to discuss the proportions between government and market operations. In addition, it is necessary to go beyond the limits of the established lines of reasoning and to seek new solutions. A stable economy depends on constructive interaction between sustainable character and sustainable culture. Therefore, the main problems of the circular economy are inextricably linked with the discussion of the existing economic paradigm.

In our opinion, there is a need for a transition from the current mechanical outlook to an organic one, where the peculiarities from of social development and bisiness communities will be oriented to increase environmental and social responcibility.

\section{REFERENCES}

Allen \& Overy, (2017). Policy levers for a low-carbon circular economy. Retrieved from https://www.circleeconomy.com/low-carbon-circular-econo...

Auzanneau, M., Calatayud, P., Gauche, M., Ghewy, X., \& Granger, M. (2017). 10 Key Indicators for Monitoring the Circular Economy. Retrieved from www.statistiques.developpementdurable.gouv.fr/.../datalab-

Brassaw, B. (2017). Germany: A Recycling Program That Actually Works. Retrieved from www.howtogermany.com/pages/recycling.html

Cavanagh, J. (2009). Alternatives to Economic Globalization: A Better World Is Possible. San Francisco: BerrettKoehler Publishers, Inc., 2009. - 408 c.

Dumas, E. (2016). Industry 4.0: how intelligent assets will be part of a circular economy industry 4.0: how intelligent assets will be part of a circular economy. Retrieved from http://www.technopropres.fr/ardi_tpss/jcms/z_7786/fr/industry-4-0-how-intelligent-assetswill-be-part-of-a-circular-economy

Eckartz, K. (2015). D3.2 Critical Raw Materials Substitution Policies - Country Profiles. Retrieved from www.criticalrawmaterials.eu/wp.../D-3.2-Country-profiles.pdf

European Commission. (2018). European innovation partnership on raw materials (EIP) high level steering group (HLSG) position paper on future orientations. Retrieved from https:/ /ec.europa.eu/docsroom/documents/27350/.../native

Faterspa group. (2018). Retrieved from https:// fatergroup.com/ru

Genoff, R. (2017). 4.0 Cities - Putting the Circular Economy to Work. Retrieved from http://www.govnews.com.au/4-0-cities-putting-the-circular-economy-to-work/

GlassOnWeb. (2014). Innovation at the heart of sita, a subsidiary of suez environnement, is making progress in Europe: In Antwerp, Belgium, a new glass recycling plant is capable of making four different colours of glass. Retrieved from www.suez-environnement.com

Gray, A. (2017). Which countries recycle the most? Retrieved 2017, from: https://www.weforum.org/agenda/2017/12/germany-recycles-more-than-any-other-country/

Hosseini, H. S. (2009). Alternative Globalizations: An Integrative Approach to Studying Dissident Knowledge in the Global Justice Movement. London: Routledge. 
Kirchherr, J., Hekkert, M., Bour, R., Huibrechtse-Truijens, A., Kostense-Smit, E., \& Muller, J. (2017). Breaking the Barriers to the Circular Economy. Retrieved from https://www.uu.nl/sites/default/files/breaking_the_barriers_to_the_circular_economy_white_p aper_web.pdf

Kraanen, F. (2017). Money makes the world go round. Retrieved from https://www.theodysseyonline.com/money-makes-the-world-

Narberhaus, M. \& Mitschke-Collande, J. (2017). Circular economy isn't a magical fix for our environmental woeshttps. Retrieved from www.theguardian.com/sustainable-business/2017/jul/14/circulareconomy-not-magical-fix-environmental-woes-global-corporations

National Intelligence Council. (2012). Alternative Worlds - Global Trends 2030. Retrieved from globaltrends2030.files.wordpress.com/2012/11/global-trends-2030-november2012.pdf.

Pleyers, G. (2013). Alter-Globalization: Becoming Actors in a Global Age. London: John Wiley \& Sons.

Probst, L., \& Frideres, L. (2016). European Union. Sustainable supply of raw materials. Optimal recycling. Retrieved from https://ec.europa.eu/growth/sectors/raw-materials/policy-strategy/...

Schlembach, R. (2016). Against Old Europe: Critical Theory and Alter-Globalization Movements. London: Routledge.

Waddingham, I. (2018). Innovation of circular economy. Retrieved from:: http://www.mooreandsmalley.co.uk/latest-blogs/innovation-circular-economy/

White, E., \& Singh Gole, R. (2013). E-Waste Recycling Technologies. Retrieved from http://www.wipo.int/edocs/pubdocs/en/patents/948/wipo_pub_948_4.pdf

Wit, M., Hoogzaad, J., Ramkumar, S., Friedl, H., \& Douma, A. (2018). The circularity gap report. Retrieved from https://www.circle-economy.com/the-circularity-gap-report-... 